\title{
Control of Post Prandial Blood Sugar Among the Treatment Patterns for Type 2 Diabetic Mellitus: A Retrospective Study
}

\author{
Malarkodi Velraj', G. Ragesh', Poripiraddy Satya Prasad² \\ 1'Department of Pharmacognosy, School of Pharmaceutical Sciences, Vels University, Chennai, Tamil Nadu, INDIA. \\ ${ }^{2}$ Department of Pharmacy Practice, Faculty of Pharmacy, Sri Ramachandra University, Porur, Chennai, Tamil Nadu, INDIA.
}

\begin{abstract}
Objective: The study mainly focused on retrospective comparison between the various treatments alternatives for good control of post prandial blood sugar in Type-2 diabetic patients. Methods: A Retrospective study was done in patients with type 2 diabetes mellitus. All the in-patients either gender, of age between 18 to 80 years were included in the study. Patients with known surgical histories, known and suspected cases of allergies and pregnant woman's were excluded from this study. Totally 120 patients was included. Result: The postprandial blood glucose results showed that significant reduction in all groups after $3^{\text {rd }}, 6^{\text {th }}$ and $18^{\text {th }}$ month of treatment as compared to first reading. When assessment between Group-A (Metformin + Acarbose) and B (Metformin + Glimepiride) express that Metformin + Acarbose (Group-A) $176.16 \pm 0.62$ have a better reduction in PPBS than Metformin + Glimepiride (Group-B) $190.58 \pm 1.7$. Conclusion: Over all, the study concludes that a combination of Metformin and Sitagliptin have a greater impact on control of post-prandial blood sugar compared to other two combinations.
\end{abstract}

Key words: Post prandial blood glucose, Diabetes mellitus, Metformin, Glimepiride and Acarbose.

\section{INTRODUCTION}

Post-meal blood glucose elevations pose a challenge to people with diabetes striving to maintain near-normal blood sugar levels. In diabetes, many epidemiological studies have shown that postprandial hyperglycemia is a contributing factor for atherosclerosis, oxidative stress, blood coagulation (increase in circulating $\mathrm{D}$-dimers and prothrombin fragments) and cardiovascular mortality. Correcting the irregularities of the postprandial state is the essential strategy for the prevention and management of cardiac diseases, particularly persons that are allied with diabetes mellitus. In the management of diabetes, health care providers usually assess glycemic control with fasting plasma glucose (FPG) and premeal glucose measurements, as well as by measuring HbA1c. ${ }^{1}$ Unfortunately, the majority of patients with diabetes fail to achieve their glycemic goals after the meal. Elevated postprandial glucose (PPG) concentrations may contribute to suboptimal glycemic control and cause earliest abnormalities of glucose homeostasis associated with type 2 diabetes. Early diagnosis and screening may help to improve the positive health outcomes in population. ${ }^{2}$ There is inadequate data to support the need for routine PPG monitoring in diabetes, except in the pregnancy state. Since selfmonitoring of blood glucose increases a significant financial and personal burden for patients. ${ }^{3}$ It is predicted that by 2030 diabetes mellitus may afflict up to 79.4 million individuals in India. ${ }^{1}$ Particularly in Tamil Nadu, 4.8 million population are affected with diabetes mellitus as of now. ${ }^{4,5}$ The decision to recommend a glucose monitoring plan should be made judiciously, accompanied with specific patient education, regular review
DOI: 10.5530/ijopp.9.2.13

Address for correspondence: G. Ragesh, Lecturer Department of Pharmacy Practice,

Faculty of Pharmacy, Sri

Ramachandra University,

Porur, Chennai, Tamil Nadu, INDIA.

Phone no: 9500013368

E-mail: gsvragesh@gmail.com

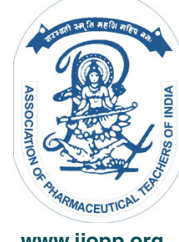

www.jopp.org 
and modifications by the health care team. Continuous medical education programmes to the health care team may be a major step in achieving target glycemic control.

\section{METHODOLOGY}

\section{Study Design}

A Retrospective study was done in patients with type 2 diabetes mellitus. Patients divided into three groups based on the combinational therapiesand the efficacy of the drugs compared between the groups. All the in-patients of either gender, of age between 18 to 80 years. Patients with past medical and medication histories included in this study. Records without proper lab parameters, deletion or addition of drugs in the above combinational therapy, surgical histories, known and suspected cases of allergies and pregnant woman's were excluded from this study. Based on the above criteria, 120 patients were included in the study.

The details of combination drugs mentioned in the below.

\begin{tabular}{lc}
\hline Groups & Combinational Therapy \\
Group A & Metformin+Acarbose $(500+25-50 \mathrm{mg})$ \\
Group B & Metformin+Glimepiride $(500+1-2 \mathrm{mg})$ \\
Group C & Metformin+Sitagliptin $(500+25-50 \mathrm{mg})$ \\
\hline
\end{tabular}

\begin{tabular}{|c|c|c|c|}
\hline \multirow{2}{*}{$\begin{array}{l}\text { Month } \\
\text { Interval }\end{array}$} & Group A & Group B & Group C \\
\hline & Mean \pm S.D & Mean \pm S.D & Mean \pm S.D \\
\hline $\begin{array}{l}\text { Initial Value/ } \\
\text { Baseline* }^{*}\end{array}$ & $206.17 \pm 2.29$ & $214.47 \pm 1.85$ & $176.16 \pm 1.62$ \\
\hline $6^{\text {th }}$ Month* & $175.02 \pm 1.32$ & $183.02 \pm 0.18$ & $182.62 \pm 0.80$ \\
\hline $12^{\text {th }}$ Month* & $162.32 \pm 1.10$ & $180.20 \pm 1.25$ & $173.77 \pm 2.45$ \\
\hline $18^{\text {th }}$ Month* & $161.12 \pm 0.52$ & $184.62 \pm 2.84$ & $159.60 \pm 1.68$ \\
\hline P-Value & 0.003 & 0.002 & 0.0177 \\
\hline
\end{tabular}

*Values in mg/dl.

Table 2: Final ANOVA Comparison Post-Prandial Blood Sugar between OHA Groups

\begin{tabular}{ccc} 
OHA Regimen & $\begin{array}{c}\text { PPBS }(\mathrm{mg} / \mathrm{dl}) \\
\text { Mean } \pm \text { S.D }\end{array}$ & P Value \\
\hline Metformin+Acarbose & $176.16 \pm 0.62$ & 0.0044 \\
Metformin+Glimepiride & $190.58 \pm 1.7$ & \\
Metformin+Sitagliptin & $163.99 \pm 1.68$ & \\
\hline
\end{tabular}

\section{RESULTS}

\section{DISCUSSION}

The post-prandial blood glucose results showed that significant reduction in all groups after $3^{\text {rd }}, 6^{\text {th }}$ and $18^{\text {th }}$ month of treatment as compared to first reading

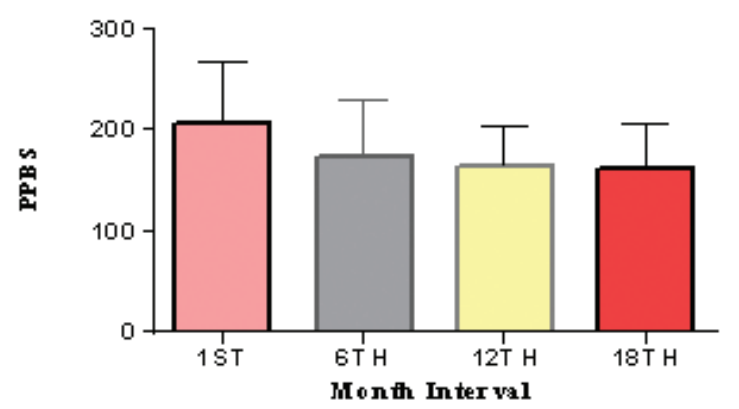

Figure 1.1: Post Prandial Blood Sugar $(\mathrm{mg} / \mathrm{dl})$ between the Month Intervals for Metformin and Acarbose

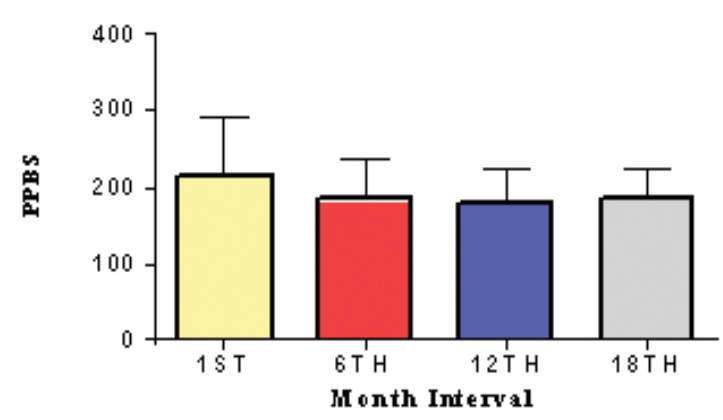

Figure 1.2: Post Prandial Blood Sugar $(\mathrm{mg} / \mathrm{dl})$ between the Month Intervals for Metformin and Glimepiride

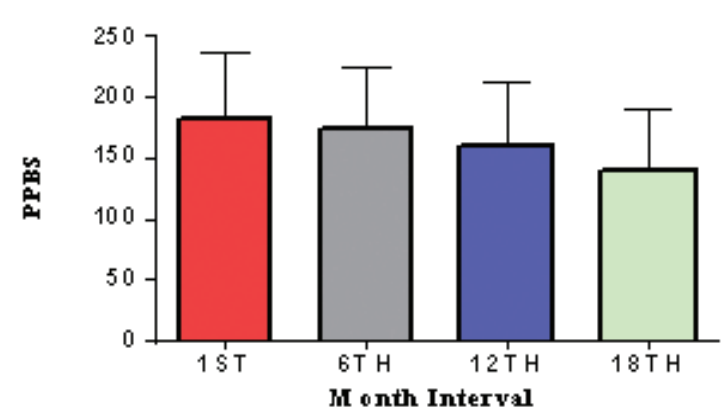

Figure 1.3: Post Prandial Blood Sugar $(\mathrm{mg} / \mathrm{dl})$ between the Month Intervals for Metformin and Sitagliptin

(Table 1, Figure 1.1, 1.2, 1.3). OHA regimengroup-C $163.99 \pm 1.68$ (Metformin+Sitagliptin) shows greater impact on PPBS than OHA regimen Group-A (Metformin+Acarbose) and B (Metformin+Glimepiride). When assessment between Group-A (Metformin+Acarbose) and B (Metformin+Glimepiride) express that Metformin+ Acarbose (Group-A) 176.16 \pm 0.62 have a better reduc- 


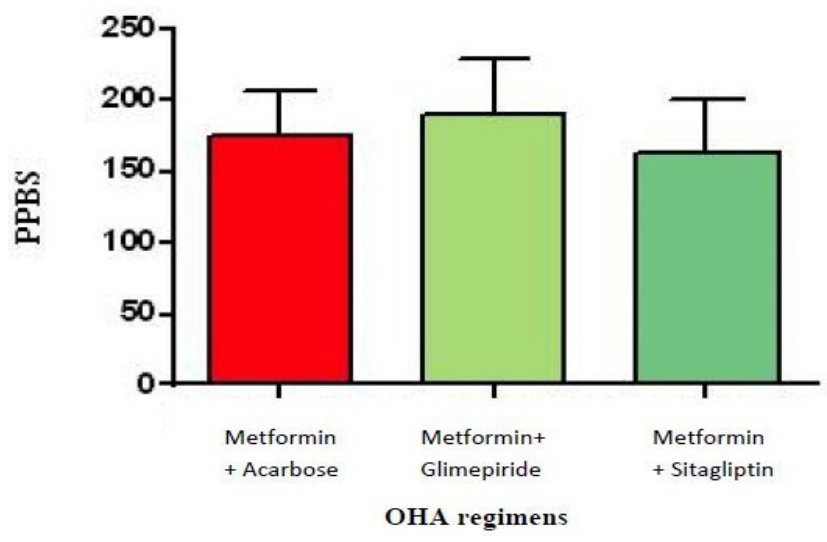

Figure 2: Comparison of PPBS profile of three OHA regimens

tion in PPBS than Metformin+Glimepiride (Group-B) $190.58 \pm 1.7$ (Table 2 and Figure 2).

\section{CONCLUSION}

Over all, the study concludes that a combination of Metformin and Sitagliptin have a greater effect on control of post-prandial blood sugar compare with other two combinations. On the other hand, this study is not supporting the safety profile of these combination therapies. Further longterm studies are needed to ensure the maximum safety and efficacy of these therapies.

\section{ACKNOWLEDGEMENT}

I take this opportunity to thank all the department faculty members for their help and support to publish this article.

\section{CONFLICT OF INTEREST}

The author declare no conflict of interest.

\section{ABBREVIATION USED}

PPBS : Post Prandial Blood Sugar; HbA1c : Glycated Heamoglobin; OHA: Oral Hypoglycemic Agent.

\section{REFERENCES}

1. Wild S, Roglic G, Green A, Sicree R, King H. Global prevalence of diabetes-estimates for the year 2000 and projections for 2030. Diabetes Care. 2004;27(5):1047-53.

2. Seema AbhijeetKaveeshwar, Jon Cornwall. The current state of diabetes mellitus in India. Australas Med J. 2014;7(1):45-8.

3. Minnie Au, Rattigan S. Barriers to the management of Diabetes Mellitus-is there a future role for Laser Doppler Flowmetry. Australas Med J. 2012;5(12):627-32.

4. Whiting Dr, Guariguata L, Weil C, Shawj. IDF Diabetes atlas: Global estimates of the prevalence of diabetes for 2011 and 2030. Diabetes Res Clin Pract. 2011;94(3):311-21.

5. Anjana RM, Ali MK, Pradeepa R, Deepa M, Datta M, Unnikrishnan R, et al. The need for obtaining accurate nationwide estimates of diabetes prevalence in India-rationale for a national study on diabetes. Indian J Med Res. 2011;133(4):369-809. 